\title{
AUTOMATIC DRIVE -SUPPORT METHOD FOR CONSTANT PRESSURE MAINTANENCE AT PUMP UNITS OF THE HYDRAULIC POWER STATIONS
}

\author{
Kudrat Abidov ${ }^{1}$, Odiljon Zaripov ${ }^{2}$, Shaxlo Zaripova ${ }^{3}$ \\ ${ }^{1}$ Head of Department, Tashkent State Technical University, Tashkent, Universitetskaya str. 2, Uzbekistan \\ ${ }^{2}$ Senior teacher, Tashkent State Technical University, Tashkent, Universitetskaya str.2, Uzbekistan \\ ${ }^{3}$ Assistant, Karshi Engineering and Economics Institute, Kashkadarya region, Karshi, Mustaqillik ave., 225, Uzbekistan
}

\begin{abstract}
In this research, the task of a water-lifting pump station is to maintain a given pressure of the pumped water regardless of its flow rate, which can vary significantly depending on many conditions Waterlifting pumping stations are designed to pump maximum flow. With this in mind, regulation methods are required to ensure the operation of pumping units at different costs.
\end{abstract}

\section{Introduction}

In the modern world, special attention is paid to the improvement of pumping stations in connection with the increased requirements for the uninterrupted supply of fields with water and the development of new areas, the task is to increase the power of power equipment and the height of water rise, to improve its design. Most drives for pumping units of pumping irrigation systems are based on an unregulated AC drive. This is often the main reason that impedes the implementation of the required water supply schedule, optimization of the operating modes of pumping stations (including cascades) according to control criteria, reducing accidents, and increasing their reliability. At the same time, as studies carried out all over the world show, the development of electric drives for pumping irrigation remains promising. In this regard, an important task is the development of scientifically grounded technical solutions that ensure the reliable operation of pumping stations and pumping units. The experience of pump stations operation shows that the main damages and accidents of pump units occur during transient processes, starts, stops, which according to the schedule of operation can be assigned several times a day, as well as in case of emergency disconnection of electric motors from the power system [1]. Pumping stations of machine irrigation systems in complex with pumping plants and power equipment make up complex hydropower system. Water-lifting pump stations include pump units equipped with AC motors, supply and discharge pipelines, transformers and switching equipment. The specified function of a water collecting pump station is to maintain the specified pressure of pumped water regardless of its flow rate, which can vary significantly depending on many conditions. Watercollecting pump stations are designed to transfer maximum flow rate. With this in mind, control methods are required to ensure operation of pump units at different flow rates. For a large group of pumping units, the economical mode is provided by stabilizing the pressure in the liquid supply system. Such plants include pumping stations of irrigation systems and the like. The need to stabilize the pressure in the network of these stations is due to the variable nature of the water consumption regime. Probabilistic nature of water consumption requires constant pressure in pump unit operation mode. The changes shall be carried out so that the required process parameters (feed, head) in the system as a whole are maintained and at the same time the minimum possible power consumption of the pump unit is ensured. This task is solved by the pump unit automatic control system, pressure stabilization [2].

\section{Experimental research}

Timely watering is a major factor affecting crop yields, particularly cotton. Therefore, the uninterrupted operation of the pumping units during the watering season to ensure a predetermined water supply schedule of the pumping station is of great national economic importance. Changes in water flow are observed during the watering season. During the period of intensive irrigation it is necessary to maintain the specified pressure of pumped water regardless of its flow rate. The Amu-Zang pump station (Fig. 1) of the first raising of the first stage is equipped with horizontal centrifugal pumps 9,10 of type 24NDS, as driving engine 5.6 three-phase asynchronous DAZO-15$59-10 \mathrm{UI}$ engines with a power of $630 \mathrm{~kW}$ are used. 


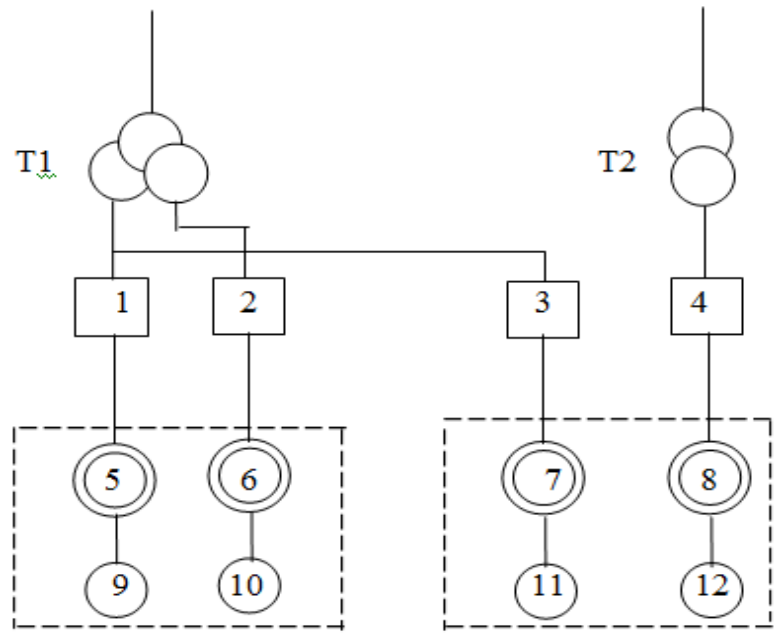

Fig.1. Pumping station of the first lift of the first stage.

Amu-Zang pump station of the first lifting of the second stage consists of analog pumps 11,12 of type 24NDS, three-phase induction motors of type DAZO-1559-10 with capacity of $800 \mathrm{~kW}$ are used as drive motor 7,8 . All of these pump station motors are powered by one substation from transformers $\mathrm{T} 1$ and T2 type TDTN25000/110/6/6, TDN-10000/110. The pump units are switched on by switching equipment $1,2,3,4$. Therefore, the Amu-Zang pump station requires control means to operate the system at different rates. It is universal to control by means of frequency converters, with the help of which it is possible to smoothly adjust the speed of rotation of the pump motor and maintain pressure in the pressure pipeline at different flow rates of pumped liquid. At minimum fluid flow rates, the pump motor rotates at a low speed only required to maintain the nominal pressure and does not consume excess energy. As the water flow rate increases, the converter increases the rotation speed of the pump motor while maintaining a predetermined pressure.

The method of automatic maintenance of constant pressure of the pump unit by the drive is performed by the following cover (Fig.2):

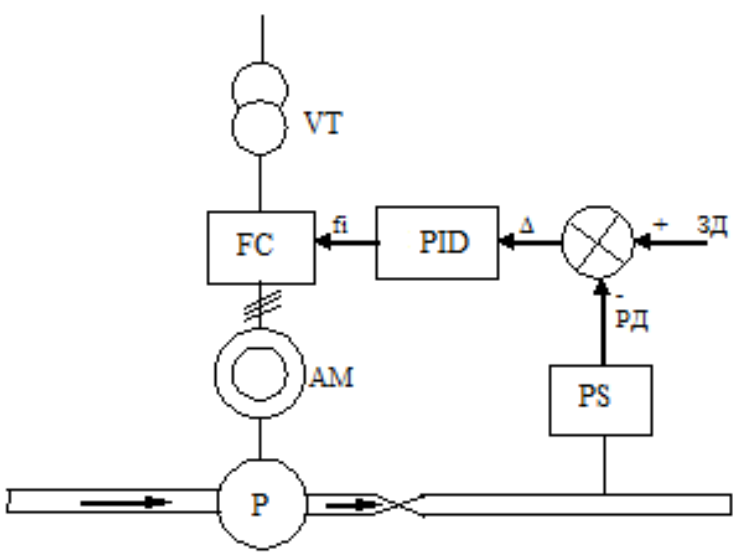

Fig.2. Automatic maintenance of the constant pressure of the pumping unit by the drive.
The input of the PID regulator 17 is supplied via the comparison unit 18 with a pressure setting signal of the MP and a real pressure signal of the RD pump unit 16 , which is received from the feedback pressure sensor 19 installed on the pressure pipeline. The deviation between the real and set $\Delta$ values will be transformed by PID regulator 17 to a frequency task signal for converter 14 . Under the influence of the setting signal $f i$, the converter 14 supplied through the transformer 13 changes the rotational speed of the motor 15 of the pump 16 and tends to bring the deviation between the preset and actual values to zero. Thus, the pressure in the system is maintained equal to the preset pressure and is independent of the flow rate. The frequency converter builds a tracking system without additional hardware costs, has built-in software functions, which allow to implement a comparison unit and a PID regulator. The transmitter only requires an external pressure sensor to implement the tracking system. The basis of maintaining constant pressure of the pump unit is the PID regulator. Its structure determines the accuracy and stability of maintaining the specified pressure, as well as the type of transient processes taking place in the pipeline when the flow rate changes.

\section{Design Studies}

Operation of PID regulator 17 in the following (Fig.3):

The output signal consists of the three components: 20 proportional $P, 21$ integrated $I$ and 22 differential $D$. The proportional component represents result of multiplication of a deviation of $\Delta$ by coefficient $K$. At increase in this coefficient the accuracy and speed of processing of a deviation increases, but stability of a system decreases and there are fluctuations.

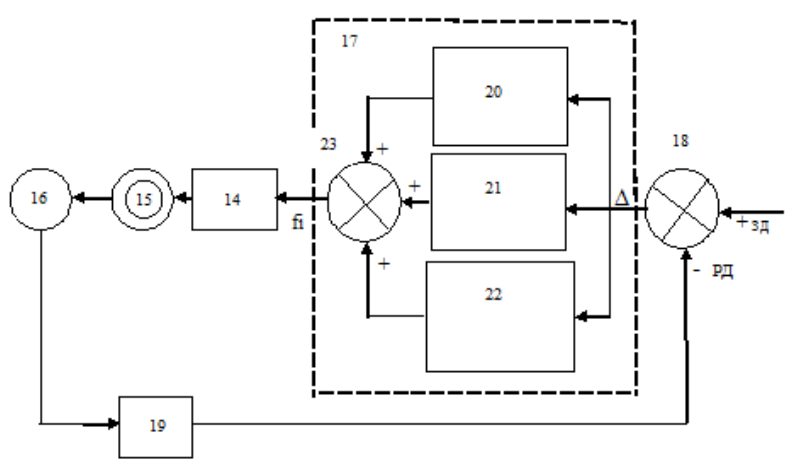

Fig.3. PID controller circuit.

To ensure accuracy while maintaining stability, integral component is introduced into the regulator structure. It represents the result of multiplication of integral of a mistake by the coefficient depending on a constant of time of integration of $\tau_{\mathrm{u}}$. Introduction of an integrated component excludes a working off error in the set mode, and time of transition process is defined by the size $\tau_{\mathrm{u}}$. At big $\tau_{\mathrm{u}}$, time of reaction to the revolting influence is big and if we want to work quicker a regulation error is necessary to reduce $\tau_{и}$. However, this can lead to system instability. For reduction of the reaction time of a system by indignation with maintaining 
stability, enter a differential component which represents the deviation differential increased by the coefficient depending on a constant of time of differentiation of $\tau_{D}$ into structure of the regulator. Introduction of differentiating component introduces damping into system and increases its stability. The more $\tau_{\mathrm{D}}$, the bigger damping impact is made by this component on a system. Signals from components 20,21,22 are summed at comparison unit 23 and transmitted to converter 14 as job $f i$. The PID regulator 17 affects the efficiency of the entire system and automatically maintains the constant pressure of the drives 15 of the pump unit 16 of the pump station.

\section{Conclusion}

The proposed automatic drive-support method for constant pressure maintenance for pump units of the hydraulic power stations ensures reliable operation of pump units, saves electric power, increases service life of the equipment.

\section{References}

1.Arshenevsky N.N., Pospelov B.B. Transient Processes of Large Pumping Stations. -M: Energy, 1980.-110 p.

2. Lesnov B.S. Power saving in pump units. - M: Energoatomizdat, 1991.-114 p.

3. Georgiadi V.H. Behavior of power units of TPP during interruptions of auxiliary power supply (Part 2) .-M.: NPF Energoprogress, 2003. - $88 \mathrm{p}$.

4. Hoshimov, F.A., Bakhadirov, I.I., Erejepov, M., Djumamuratov, B. (2019) Development of method for normalizing electricity consumption E3S Web Conf 139 doi:10.1051/e3sconf/201913901074

5. Glovatski O.J., Ergashev R.R., Norov B.H. Analysis of Failures of Components of Machine Water Removal Systems / /Materials of TIIM International Conference November 27-29, 2008.

6. Glovatski O.J., Gufranov A.A., Uralov B.R., Ergashev R.R. Improving the Reliability of Operation of Water Supply Facilities of Large Pumping Stations //Materials of TIIM International Conference November 27-29, 2008. 7.Kamalov T.S., Muminov K., Ishnazarov O.H. Transmission coefficient of functional converter of asynchronous electric drive system with frequency control // Uzbek magazine "Problems of informatics and energy." 2003. №4. - p.32-37.

8. Kamalov T.S. Current state and trend of development of electric drives of industrial and agricultural installations // Uzbek magazine "Problems of informatics and energy" №1, 2004. - p.50-58.

9.Sokolov E.I., Baru A.Y., Shindnes U.L. et al. Experience of development and implementation of frequency converters for adjustable electric drive of pump units of main oil pipelines // Electrical engineering - 2004. - №7.-p.52-57.

10. Hoshimov, F.A., Bakhadirov, I.I., Erejepov, M., Djumamuratov, B. (2019) Development of method for normalizing electricity consumption $E 3 S \mathrm{Web}$ Conf 139 doi:10.1051/e3sconf/201913901074

11.Khashimov A.A., Abidov K.G. Self-launch of pumping units. -T.: TSTU, 2002. $-112 \mathrm{p}$.

12. Hashimov A.A., Abidov K.G. Method of automatic maintenance by the drive of constant pressure of the pump unit of the pump station. RUZ patent.IAP 20030032 , 15.01.2003, IAP 02954.

13. Abidov K.G. Determination of critical power supply break time for self-start of pump units // Journal "Power and resource saving problems" TSTU - Tashkent, 2017. №3-4.- p.160-165.

14.Abidov K.G. Self-launch of electric motors for the purpose of energy and resource saving in pumping stations // Magazine "Science and world." -Volgohrad. 2018. - №6(58). - p.8-10.

15.Abidov K.G. Analysis of self-starting modes of pumping motors. International journal of advanced research in science, engineering and technology. July 2019. India. Vol.6, Issue 7.p.8721-8724. 